\title{
Prognostic Factors and a Survival Score in Patients Irradiated for Metastatic Epidural Spinal Cord Compression from Urothelial Carcinoma Cancer of the Bladder
}

\author{
DIRK RADES ${ }^{1}$, LISA SONDERMANN ${ }^{1}$, LAURA MOTISI $^{1}$, \\ STEFAN JANSSEN ${ }^{1,2}$, JON CACICEDO ${ }^{3}$ and STEVEN E. SCHILD ${ }^{4}$ \\ ${ }^{1}$ Department of Radiation Oncology, University of Lübeck, Lübeck, Germany; \\ ${ }^{2}$ Medical Practice of Radiotherapy and Radiation Oncology, Hannover, Germany; \\ ${ }^{3}$ Department of Radiation Oncology, Cruces University Hospital, Barakaldo, Vizkaya, Spain; \\ ${ }^{4}$ Department of Radiation Oncology, Mayo Clinic, Scottsdale, AZ, U.S.A.
}

\begin{abstract}
Background/Aim: Prognoses of patients with metastatic epidural spinal cord compression (MESCC) from urothelial carcinoma of the bladder are generally poor. This study aimed to identify prognostic factors that can facilitate personalized care of these patients. Patients and Methods: In 46 patients, 10 factors were evaluated for overall response $(O R)$, post-radiotherapy (RT) ambulatory status, local control of MESCC and overall survival (OS). Independent predictors of OS were incorporated in a scoring system. Results: Being ambulatory post-RT was associated with pre-RT ambulatory status $(p<0.001)$ and better performance score $(p<0.001)$. No factor was significantly associated with OR and local control. On multivariate analyses, lack of visceral metastases $(p=0.002)$, being ambulatory pre-RT $(p=0.001)$ and performance score 1-2 $(p=0.004)$ were associated with improved OS. Based on these factors, there were three distinct prognostic groups with 0,1-2 and 3 points and median OS times of 2, 4 and 11.5 months, respectively. Conclusion: Prognostic factors were identified and a new survival score was created that will help physicians aiming to personalize treatment for patients with MESCC from urothelial carcinoma of the bladder.
\end{abstract}

Since metastatic epidural spinal cord compression (MESCC) is a palliative situation, personalized treatments for patients

Correspondence to: Dirk Rades, MD, Department of Radiation Oncology, University of Lübeck, Lübeck, Ratzeburger Allee 160, 23562 Lübeck, Germany. Tel: +49 45150045401, Fax: +49 45150045404, e-mail: Rades.Dirk@gmx.net

Key Words: Urothelial carcinoma, metastatic epidural spinal cord compression, radiation therapy, treatment outcomes, prognostic factors, survival score. are very important $(1,2)$. Tailoring the treatment to a patient's specific situation should include the attempt to avoid over- and under-treatment. This means that patients with a very poor overall survival (OS) should preferably receive a less aggressive treatment that will not significantly impair quality of life during their short remaining lifespan. Moreover, treatment should be kept as short as reasonably possible to give the patients as many days as possible without receiving anticancer treatment $(3,4)$. Late treatmentrelated morbidity plays only a minor role for patients with a limited OS prognosis, who likely will die before they would have experienced such morbidity. On the contrary, in patients with longer survival, durable local control of MESCC and late morbidity due to anticancer treatment become an issue, and the focus of treatment changes from short overall treatment time to persistent local control with fewer and less severe late sequelae (5-7). In addition to OS, other endpoints are important, including response to treatment, posttreatment ambulatory status and local control of MESCC (17). Selection of a personalized treatment approach should take into account all these endpoints and it would be important to identify prognostic factors for each.

In order to provide an optimal personalized treatment, it would be desirable to have a detailed understanding of prognostic factors for the different primary tumour types that show a considerable variety with respect to their biological behaviour and prognoses $(1,2,8)$. The present study focused on patients irradiated for MESCC from urothelial carcinoma of the bladder, which are quite rare and account for only about $2 \%$ of patients receiving radiotherapy (RT) for MESCC (9). In addition to the investigation of potential associations between 10 clinical factors and response, postRT ambulatory status, local control of MESCC and OS, this study aimed to create a new OS score specifically for this cohort of patients 
Table I. Overall response to radiotherapy $(R T)$ according to patient characteristics.

\begin{tabular}{|c|c|c|}
\hline Characteristic & $\begin{array}{c}\text { Overall response, } \\
\mathrm{N}(\%)\end{array}$ & $p$-Value \\
\hline \multicolumn{3}{|l|}{ Age } \\
\hline$\leq 65$ Years $(\mathrm{N}=23)$ & $21(91)$ & 0.52 \\
\hline$\geq 66$ Years $(\mathrm{N}=23)$ & $17(74)$ & \\
\hline \multicolumn{3}{|l|}{ Interval from diagnosis } \\
\hline \multicolumn{3}{|l|}{ of UC to RT of MESCC } \\
\hline$\leq 15$ Months $(\mathrm{N}=21)$ & $16(76)$ & 0.67 \\
\hline$>15$ Months $(\mathrm{N}=25)$ & $22(88)$ & \\
\hline \multicolumn{3}{|l|}{ Visceral metastases } \\
\hline No $(\mathrm{N}=22)$ & $16(73)$ & 0.47 \\
\hline Yes $(\mathrm{N}=24)$ & $22(92)$ & \\
\hline \multicolumn{3}{|l|}{ Additional bone metastases } \\
\hline No $(\mathrm{N}=12)$ & $8(67)$ & 0.48 \\
\hline Yes $(\mathrm{N}=34)$ & $30(88)$ & \\
\hline \multicolumn{3}{|l|}{ Gender } \\
\hline Female $(\mathrm{N}=5)$ & $4(80)$ & 0.96 \\
\hline Male $(\mathrm{N}=41)$ & $34(83)$ & \\
\hline \multicolumn{3}{|c|}{ Time developing motor dysfunction } \\
\hline$\leq 7$ Days $(\mathrm{N}=20)$ & $15(75)$ & 0.62 \\
\hline$>7$ Days $(\mathrm{N}=26)$ & $23(88)$ & \\
\hline \multicolumn{3}{|l|}{ Pre-RT ambulatory status } \\
\hline Not ambulatory $(\mathrm{N}=26)$ & $20(77)$ & 0.62 \\
\hline Ambulatory $(\mathrm{N}=20)$ & $18(90)$ & \\
\hline \multicolumn{3}{|c|}{ Number of involved vertebrae } \\
\hline $1-2(\mathrm{~N}=14)$ & $11(79)$ & 0.83 \\
\hline$\geq 3(\mathrm{~N}=32)$ & $27(84)$ & \\
\hline \multicolumn{3}{|l|}{ ECOG-PS } \\
\hline $1-2(\mathrm{~N}=16)$ & $16(100)$ & 0.34 \\
\hline $3-4(\mathrm{~N}=30)$ & $22(73)$ & \\
\hline \multicolumn{3}{|l|}{ Total dose of RT (EQD2) } \\
\hline$<25$ Gy $(\mathrm{N}=22)$ & $18(82)$ & 0.95 \\
\hline$>30$ Gy $(\mathrm{N}=24)$ & $20(83)$ & \\
\hline Entire cohort & $38(83)$ & \\
\hline
\end{tabular}

MESCC: Metastatic spinal cord compression; ECOG-PS: Eastern Cooperative Oncology Group performance score; EQD2: equivalent dose in 2-Gy fractions; UC: urothelial carcinoma.

\section{Patients and Methods}

Forty-six patients (32 previously reported and 14 new patients) were included in this retrospective study and had received palliative RT for MESCC from urothelial carcinoma of the bladder associated with motor dysfunction of the lower extremities (9). Investigated endpoints included overall response (OR) to RT (defined as improvement or no further progression of motor dysfunction), post-RT ambulatory status, local control of MESCC (defined as no in-field recurrence of MESCC following RT) and OS. In order to determine OR, the best response during the follow-up period of up to 6 months was considered. Time to in-field recurrence and time to death were counted from the last day of RT. The analyses of local control of MESCC were limited to those patients who responded to RT.

In addition to the outcomes of the entire cohort, associations of 10 potential prognostic factors with these endpoints were investigated. The 10 factors were age ( $\leq 65 v s . \geq 66$ years, median 65.5 years),
Table II. Ambulatory rates following radiotherapy (RT) of metastatic spinal cord compression (MESCC) according to patient characteristics.

\begin{tabular}{|c|c|c|}
\hline Characteristic & $\begin{array}{c}\text { Ambulatory, } \\
\mathrm{N}(\%)\end{array}$ & $p$-Value \\
\hline \multicolumn{3}{|l|}{ Age } \\
\hline$\leq 65$ Years $(\mathrm{N}=23)$ & $14(61)$ & 0.20 \\
\hline$\geq 66$ Years $(\mathrm{N}=23)$ & $8(35)$ & \\
\hline \multicolumn{3}{|l|}{ Interval from diagnosis of } \\
\hline \multicolumn{3}{|l|}{ UC to RT of MESCC } \\
\hline$\leq 15$ Months $(\mathrm{N}=21)$ & $7(33)$ & 0.20 \\
\hline$>15$ Months $(\mathrm{N}=25)$ & $15(60)$ & \\
\hline \multicolumn{3}{|l|}{ Visceral metastases } \\
\hline No $(\mathrm{N}=22)$ & $12(55)$ & 0.52 \\
\hline Yes $(\mathrm{N}=24)$ & $10(42)$ & \\
\hline \multicolumn{3}{|l|}{ Additional bone metastases } \\
\hline No $(\mathrm{N}=12)$ & $6(50)$ & 0.88 \\
\hline Yes $(\mathrm{N}=34)$ & $16(47)$ & \\
\hline \multicolumn{3}{|l|}{ Gender } \\
\hline Female $(\mathrm{N}=5)$ & $2(40)$ & 0.78 \\
\hline Male $(\mathrm{N}=41)$ & $20(49)$ & \\
\hline \multicolumn{3}{|c|}{ Time developing motor dysfunction } \\
\hline$\leq 7$ Days $(\mathrm{N}=20)$ & $6(30)$ & 0.12 \\
\hline >7 Days $(\mathrm{N}=26)$ & $16(62)$ & \\
\hline \multicolumn{3}{|l|}{ Pre-RT ambulatory status } \\
\hline Not ambulatory $(\mathrm{N}=26)$ & $3(12)$ & $<0.001$ \\
\hline Ambulatory $(\mathrm{N}=20)$ & $19(95)$ & \\
\hline \multicolumn{3}{|c|}{ Number of involved vertebrae } \\
\hline $1-2(\mathrm{~N}=14)$ & $9(64)$ & 0.29 \\
\hline$\geq 3(\mathrm{~N}=32)$ & $13(41)$ & \\
\hline \multicolumn{3}{|l|}{ ECOG-PS } \\
\hline $1-2(\mathrm{~N}=16)$ & $15(94)$ & $<0.001$ \\
\hline $3-4(\mathrm{~N}=30)$ & $7(23)$ & \\
\hline \multicolumn{3}{|l|}{ Total dose of RT (EQD2) } \\
\hline$<25$ Gy $(\mathrm{N}=22)$ & $10(45)$ & 0.83 \\
\hline$>30$ Gy $(\mathrm{N}=24)$ & $12(50)$ & \\
\hline Entire cohort & $22(48)$ & \\
\hline
\end{tabular}

ECOG-PS: Eastern Cooperative Oncology Group performance score; EQD2: equivalent dose in 2-Gy fractions; UC: urothelial carcinoma. Bold indicates significant $p$-Values.

interval between diagnosis of urothelial carcinoma and RT of MESCC ( $\leq 15 v s .>15$ months), presence of visceral metastases at the start of RT (no $v s$. yes), additional bone metastases (no $v s$. yes), gender, time of developing motor dysfunction prior to RT ( $\leq 7 v s .>7$ days), preRT ambulatory status (no $v s$. yes), number of vertebrae involved by MESCC, (1-2 vs. $\geq 3)$, Eastern Cooperative Oncology Group performance score (ECOG-PS) (1-2 vs. 3-4) and the total RT dose given as equivalent dose in 2 Gy fractions (EQD2) using an $\alpha / \beta$-ratio of $10 \mathrm{~Gy}$ for tumour cell kill (<25 vs. $>30 \mathrm{~Gy})(10)$.

The statistical analyses regarding OR and post-RT ambulatory status were performed with the Chi-square test. For the analyses of local control of MESCC and OS, the Kaplan-Meier method (11) and the Wilcoxon test were used (=univariate analyses). For all endpoints, $p$-values of less than 0.05 were regarded as significant. Those factors achieving significance on the univariate analyses of local control of MESCC and OS were additionally analysed in a multivariate manner using the Cox proportional hazards model. 
Table III. Local control of metastatic spinal cord compression (MESCC) at 3, 6, 9 and 12 months following radiotherapy (RT) according to patient characteristics. These analyses were performed in those 38 patients who responded to $R T$.

\begin{tabular}{|c|c|c|c|c|c|}
\hline Characteristic & 3 Months $(\%)$ & 6 Months $(\%)$ & 9 Months $(\%)$ & 12 Months (\%) & $p$-Value \\
\hline \multicolumn{6}{|l|}{ Age } \\
\hline$\leq 65$ Years $(\mathrm{N}=21)$ & 93 & 93 & 78 & n.a. & \multirow[t]{2}{*}{0.88} \\
\hline$\geq 66$ Years $(\mathrm{N}=17)$ & 93 & 92 & 92 & 92 & \\
\hline \multicolumn{6}{|c|}{ Interval from diagnosis of UC to RT of MESCC } \\
\hline$\leq 15$ Months $(\mathrm{N}=16)$ & 92 & 92 & 92 & 92 & \multirow[t]{2}{*}{0.92} \\
\hline$>15$ Months $(\mathrm{N}=22)$ & 94 & 94 & 80 & 0 & \\
\hline \multicolumn{6}{|l|}{ Visceral metastases } \\
\hline No $(\mathrm{N}=16)$ & 93 & 93 & 82 & 41 & \multirow[t]{2}{*}{0.96} \\
\hline Yes $(\mathrm{N}=22)$ & 92 & 92 & 92 & n.a. & \\
\hline \multicolumn{6}{|l|}{ Additional bone metastases } \\
\hline No $(\mathrm{N}=8)$ & 83 & 83 & 42 & n.a. & \multirow[t]{2}{*}{0.16} \\
\hline Yes $(\mathrm{N}=30)$ & 95 & 95 & 95 & 48 & \\
\hline \multicolumn{6}{|l|}{ Gender } \\
\hline Female $(\mathrm{N}=4)$ & 67 & 67 & 67 & n.a. & \multirow[t]{2}{*}{0.09} \\
\hline Male $(\mathrm{N}=34)$ & 96 & 96 & 84 & 42 & \\
\hline \multicolumn{6}{|c|}{ Time developing motor dysfunction } \\
\hline$\leq 7$ Days $(\mathrm{N}=15)$ & 89 & 89 & 89 & 0 & \multirow[t]{2}{*}{0.55} \\
\hline >7 Days $(\mathrm{N}=23)$ & 95 & 95 & 83 & 55 & \\
\hline \multicolumn{6}{|l|}{ Pre-RT ambulatory status } \\
\hline Not ambulatory $(\mathrm{N}=20)$ & 100 & 100 & 100 & n.a. & \multirow[t]{2}{*}{0.17} \\
\hline Ambulatory $(\mathrm{N}=18)$ & 88 & 88 & 77 & 26 & \\
\hline \multicolumn{6}{|c|}{ Number of involved vertebrae } \\
\hline $1-2(\mathrm{~N}=11)$ & 89 & 89 & 59 & 59 & \multirow[t]{2}{*}{0.46} \\
\hline$\geq 3(\mathrm{~N}=27)$ & 95 & 95 & 95 & n.a. & \\
\hline \multicolumn{6}{|l|}{ ECOG-PS } \\
\hline $1-2(N=16)$ & 87 & 87 & 74 & 25 & \multirow[t]{2}{*}{0.13} \\
\hline $3-4(\mathrm{~N}=22)$ & 100 & 100 & 100 & n.a. & \\
\hline \multicolumn{6}{|l|}{ Total dose of RT (EQD2) } \\
\hline$<25$ Gy $(\mathrm{N}=18)$ & 86 & 86 & 64 & 64 & \multirow[t]{3}{*}{0.12} \\
\hline$>30$ Gy $(\mathrm{N}=20)$ & 100 & 100 & 100 & n.a. & \\
\hline Entire cohort & 93 & 93 & 83 & 41 & \\
\hline
\end{tabular}

ECOG-PS: Eastern Cooperative Oncology Group performance score; EQD2: equivalent dose in 2 Gy fractions; UC: urothelial carcinoma; n.a.: not available. Bold indicates significant $p$-Values.

Subsequently, the factors that proved to be independently associated with OS were incorporated in a scoring system that allows estimating the OS probability of individual patients.

\section{Results}

Patients were followed-up until death, or for a median of 10 months in patients alive at the last follow-up. Considering the entire cohort, the OR rate was $83 \%$ (11\% with improvement and $72 \%$ with no further progression of motor dysfunction). None of the 10 investigated factors were significantly associated with OR (Table I). Post-RT, $48 \%$ of the entire cohort were ambulatory, and this was significantly associated with being ambulatory pre-RT $(p<0.001)$ and with an ECOG-PS of $1-2 \quad(p<0.001)$. Three out of 26 nonambulatory patients (12\%) regained the ability to walk after RT, and 19 out of 20 ambulatory patients (95\%) maintained ambulation. The ambulatory rates post-RT according to all investigated factors are given in Table II. Considering the entire cohort, the local control rates at 3, 6,9 and 12 months following RT were $93 \%, 93 \%, 83 \%$ and $41 \%$, respectively. On univariate analyses of local control of MESCC, no factor proved to be significantly associated with outcomes. The local control rates are summarized in Table III.

Median OS time was 3.5 months considering the entire cohort, and OS rates at 3, 6, 9 and 12 months following RT were $50 \%, 26 \%, 18 \%$ and $16 \%$, respectively. On univariate analyses of OS, significant associations with improved outcomes were found for absence of visceral metastases ( $p=0.017$ ), a time of developing motor dysfunction of $>7$ days (representing a slower development of motor deficits) $(p=0.026)$, ambulatory status pre-RT $(p<0.001)$ and an ECOG-PS of $1-2(p<0.001)$. The results of the univariate analyses of OS are summarized in Table IV. On subsequent multivariate analyses of OS, lack of visceral metastases 
Table IV. Overall survival of patients (MESCC) at 3, 6, 9 and 12 months following radiotherapy (RT) for metastatic spinal cord compression according to patient characteristics.

\begin{tabular}{|c|c|c|c|c|c|}
\hline Characteristic & 3 Months $(\%)$ & 6 Months $(\%)$ & 9 Months $(\%)$ & 12 Months (\%) & $p$-Value \\
\hline \multicolumn{6}{|l|}{ Age } \\
\hline$\leq 65$ Years $(\mathrm{N}=23)$ & 57 & 30 & 21 & 21 & \multirow[t]{2}{*}{0.51} \\
\hline$\geq 66$ Years $(\mathrm{N}=23)$ & 43 & 22 & 16 & 11 & \\
\hline \multicolumn{6}{|c|}{ Interval from diagnosis of UC to RT of MESCC } \\
\hline$\leq 15$ Months $(\mathrm{N}=21)$ & 48 & 19 & 19 & 19 & \multirow[t]{2}{*}{0.57} \\
\hline$>15$ Months $(\mathrm{N}=25)$ & 52 & 32 & 20 & 16 & \\
\hline \multicolumn{6}{|l|}{ Visceral metastases } \\
\hline No $(\mathrm{N}=22)$ & 68 & 50 & 34 & 28 & \multirow[t]{2}{*}{$\mathbf{0 . 0 1 7}$} \\
\hline Yes $(\mathrm{N}=24)$ & 33 & 4 & 4 & n.a. & \\
\hline \multicolumn{6}{|l|}{ Additional bone metastases } \\
\hline No $(\mathrm{N}=12)$ & 42 & 25 & 17 & 8 & \multirow[t]{2}{*}{0.67} \\
\hline Yes $(\mathrm{N}=34)$ & 53 & 26 & 19 & 19 & \\
\hline \multicolumn{6}{|l|}{ Gender } \\
\hline Female $(\mathrm{N}=5)$ & 60 & 40 & 20 & 0 & \multirow[t]{2}{*}{0.92} \\
\hline Male $(\mathrm{N}=41)$ & 49 & 24 & 19 & 19 & \\
\hline \multicolumn{6}{|c|}{ Time developing motor dysfunction } \\
\hline$\leq 7$ Days $(\mathrm{N}=20)$ & 35 & 15 & 15 & 8 & \multirow[t]{2}{*}{$\mathbf{0 . 0 2 6}$} \\
\hline >7 Days $(\mathrm{N}=26)$ & 62 & 35 & 22 & 22 & \\
\hline \multicolumn{6}{|l|}{ Pre-RT ambulatory status } \\
\hline Not ambulatory $(\mathrm{N}=26)$ & 23 & 8 & 8 & n.a. & \multirow[t]{2}{*}{$<0.001$} \\
\hline Ambulatory $(\mathrm{N}=20)$ & 85 & 50 & 34 & 28 & \\
\hline \multicolumn{6}{|c|}{ Number of involved vertebrae } \\
\hline $1-2(\mathrm{~N}=14)$ & 50 & 29 & 21 & 14 & \multirow[t]{2}{*}{0.75} \\
\hline$\geq 3(\mathrm{~N}=32)$ & 50 & 25 & 17 & 17 & \\
\hline \multicolumn{6}{|l|}{ ECOG-PS } \\
\hline $1-2(N=16)$ & 88 & 50 & 38 & 31 & \multirow[t]{2}{*}{$<0.001$} \\
\hline $3-4(\mathrm{~N}=30)$ & 30 & 13 & 7 & n.a. & \\
\hline \multicolumn{6}{|l|}{ Total dose of RT (EQD2) } \\
\hline$<25$ Gy $(\mathrm{N}=22)$ & 59 & 27 & 22 & 16 & \multirow[t]{2}{*}{0.39} \\
\hline$>30$ Gy $(\mathrm{N}=24)$ & 42 & 25 & 15 & 15 & \\
\hline Entire cohort & & 50 & 26 & 18 & 16 \\
\hline
\end{tabular}

ECOG-PS: Eastern Cooperative Oncology Group performance score; EQD2: equivalent dose in 2 Gy fractions; UC: urothelial carcinoma; n.a.: not available. Bold indicates significant $p$-Values.

Table V. Overall survival according to total prognostic score $(0,1,2$ and 3 points) and the three prognostic groups.

\begin{tabular}{|c|c|c|c|c|c|c|}
\hline & Points & 3 Months (\%) & 6 Months (\%) & 9 Months (\%) & 12 Months (\%) & $p$-Value \\
\hline \multirow[t]{4}{*}{ Prognostic score } & $0(\mathrm{~N}=13)$ & 8 & 0 & 0 & 0 & $<0.001$ \\
\hline & $1(\mathrm{~N}=16)$ & 38 & 13 & 13 & n.a. & \\
\hline & $2(\mathrm{~N}=9)$ & 89 & 33 & 17 & n.a. & \\
\hline & $3(\mathrm{~N}=8)$ & 100 & 88 & 63 & 50 & \\
\hline \multirow[t]{3}{*}{ Prognostic group } & $0(\mathrm{~N}=13)$ & 8 & 0 & 0 & 0 & 0.001 \\
\hline & $1-2(\mathrm{~N}=25)$ & 56 & 20 & 13 & n.a. & \\
\hline & $3(\mathrm{~N}=8)$ & 100 & 88 & 63 & 50 & \\
\hline
\end{tabular}

n.a.: Not available. Bold indicates significant $p$-Values.

[hazard ratio $(\mathrm{HR})=3.24,95 \%$ confidence interval $(\mathrm{CI})=1.54$ $7.12, p=0.002]$, ambulatory status pre-RT ( $\mathrm{HR}=3.58,95 \%$ $\mathrm{CI}=1.67-8.00, p=0.001)$ and ECOG-PS of $1-2(\mathrm{HR}=3.34,95 \%$ $\mathrm{CI}=1.48-7.95, p=0.004)$ maintained significance, whereas the time of developing motor dysfunction $>7$ days was no longer significant $(\mathrm{HR}=1.66,95 \%$-CI $=0.84-3.27, p=0.14)$.

These three independent predictors of OS, visceral metastases, pre-RT ambulatory status and ECOG-PS, were 


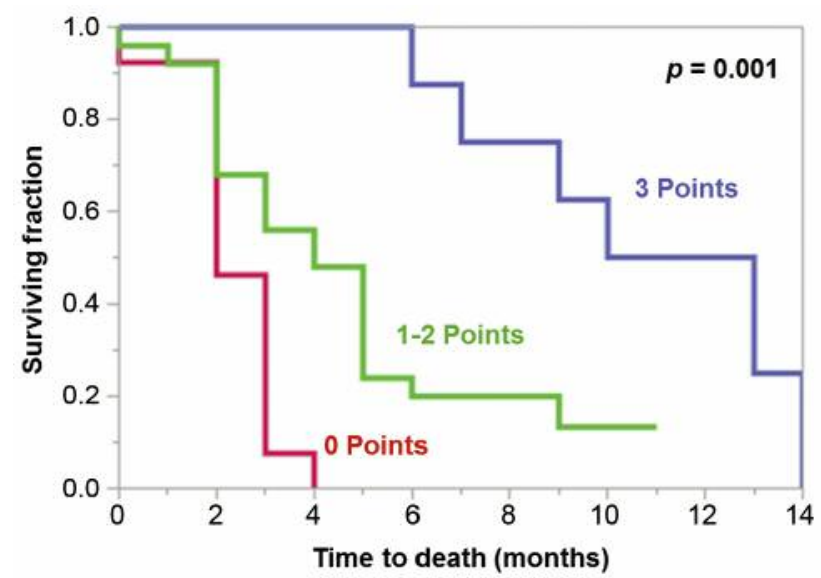

Figure 1. Kaplan-Meier curves of survival according to the three prognostic groups with 0 points, 1-2 points and 3 points.

used to create the scoring system for estimating OS. The following scoring points were assigned (factor scores): visceral metastases $=0$ points, no visceral metastases $=1$ point; not ambulatory $=0$ points, ambulatory $=1$ point; ECOG-PS of $3-4=0$ points and ECOG-PS of $1-2=1$ point. To obtain the total score for an individual patient, the three factor scores were summed. Thus, patient scores were $0,1,2$ and 3 points. The corresponding OS rates at 3, 6,9 and 12 months are shown in Table V. Based on the OS rates according to patient scores, three prognostic groups (0 points, $1-2$ points, 3 points) with significantly different OS rates were designated (Table V, Figure $1, p=0.001)$. The median OS times of these groups were 2 months, 4 months and 11.5 months, respectively.

\section{Discussion}

MESCC has been reported to occur in up to $10 \%$ of adult patients with cancer $(1,2)$. About $2 \%$ of these patients have urothelial carcinoma of the bladder. In a previous retrospective study of 32 patients treated with RT alone, the median OS time was only 4 months (9). However, $16 \%$ of patients survived for 1 year or longer following RT. There is general agreement that patients with MESCC and a short remaining survival time should preferably be treated with single-fraction or short-course multi-fraction RT, e.g. $1 \times 8$ Gy or $5 \times 4$ Gy in 1 week (1-4). These RT programs were found to be similarly effective with respect to improving or maintaining motor function than longer-course RT programs such as $10 \times 3 \mathrm{~Gy}$ in 2 weeks, $15 \times 2.5$ Gy in 3 weeks or $20 \times 2$ Gy in 4 weeks $(3,4)$. However, longer-course programs were reported to provide better local control of MESCC than single-fraction or shortcourse RT $(5,6,12)$. Moreover, patients with a favourable OS prognosis may even benefit form doses higher than $10 \times 3 \mathrm{~Gy}$
(EQD2=32.5 Gy). In a retrospective matched-pair study of patients with favourable survival prognoses, 191 patients receiving $10 \times 3$ Gy in 2 weeks were matched 1:1 to 191 patients receiving $15 \times 2.5$ Gy in 3 weeks $(\mathrm{EQD} 2=39.1 \mathrm{~Gy})$ or $20 \times 2$ Gy in 4 weeks (EQD2=40 Gy) for 10 clinical factors (7). In the higher-dose groups, both local control of MESCC $(p=0.012)$ and OS $(p=0.013)$ were significantly better. These data show that it is very important to be able to estimate an individual patient's OS prognosis prior to the start of treatment, in order to prescribe the most appropriate RT program. Therefore, prognostic factors were identified and survival scores were developed for patients with MESCC in general and additionally for MESSC from specific primary tumour types such as breast, prostate and lung cancer, as well as several others $(8,13-17)$.

In the present study, the first OS score was created particularly for patients irradiated for MESCC from urothelial carcinoma of the bladder and is, therefore, much more specific than a previous score developed for metastatic bladder cancer in general, including patients with metastases to the brain and other sites (18). Based on the three independent prognostic factors, visceral metastases, pre-RT ambulatory status and ECOG-PS, a tool was designed including three prognostic groups. Patients achieving 0 points had a median OS time of only 2 months and none of these patients survived longer than 4 months. Therefore, such patients appear to be good candidates for short-course RT with $5 \times 4$ Gy or even singlefraction RT with $1 \times 8 \mathrm{~Gy}$. In the group of patients achieving 1-2 points, the median OS time was 4 months, and only $20 \%$ of the patients survived 6 months or longer. Thus, short-course RT with $5 \times 4$ Gy appears appropriate, $10 \times 3$ Gy in 2 weeks may also be considered. Those patients achieving 3 points had the most favourable OS prognosis, with a median OS time of 11.5 months; $88 \%$ of the patients survived 6 months or longer. Therefore, these patients should receive longer-course RT, preferentially with an EQD2 doses higher than the EQD2 of $10 \times 3$ Gy (7).

This study also investigated response to RT and ambulatory status post-RT. RT was able to improve, or at least avoid further progression of motor dysfunction in $83 \%$ of the patients. However, improvement of motor deficits was achieved only in $11 \%$ of patients. Of those patients who were not ambulatory prior to RT, only $12 \%$ regained the ability to walk after treatment, whereas $95 \%$ of ambulatory patients maintained this status. Since the proportion of patients showing improvement of motor function is small, upfront decompressive surgery plus stabilization in addition to RT appears to be indicated for many patients with MESCC from urothelial carcinoma of the bladder. A previous randomized trial of 101 patients demonstrated that upfront surgery significantly increased the rate of ambulation for patients who met certain criteria, including a relatively good PS, involvement of only one spinal segment by MESCC and an 
expected OS of at least 3 months (19). Therefore, patients with MESCC from urothelial carcinoma of the bladder who meet these criteria should strongly be considered for upfront decompressive surgery plus stabilization, particularly those patients who are not ambulatory for a short period. When following these recommendations, the retrospective design of the present study should be considered, since retrospective studies bear a risk of hidden selection biases.

In summary, a new score system was developed for patients with MESCC form urothelial carcinoma of the bladder that can help radiation oncologists choose the best RT program for an individual patient. Furthermore, the rate of improvement of motor dysfunction following RT was low; so was the rate of non-ambulatory patients who regained the ability to walk. Thus, upfront decompressive surgery plus stabilization should be strongly considered for patients who meet the criteria used in a previous randomized trial (19).

\section{References}

1 Rades D and Abrahm JL: The role of radiotherapy for metastatic epidural spinal cord compression. Nat Rev Clin Oncol 7: 590598, 2010.

2 Prasad D and Schiff D: Malignant spinal cord compression. Lancet Oncol 6: 15-24, 2005.

3 Rades D, Stalpers LJA, Veninga T, Schulte R, Hoskin PJ, Obralic N, Bajrovic A, Rudat V, Schwarz R, Hulshof MC, Poortmans $\mathrm{P}$ and Schild SE: Evaluation of five radiation schedules and prognostic factors for metastatic spinal cord compression in a series of 1304 patients. J Clin Oncol 23: 33663375, 2005.

4 Rades D, Šegedin B, Conde-Moreno AJ, Garcia R, Perpar A, Metz M, Badakhshi H, Schreiber A, Nitsche M, Hipp P, Schulze W, Adamietz IA, Norkus D, Rudat V, Cacicedo J and Schild SE: Radiotherapy With 4 Gy $\times 5$ versus $3 \mathrm{~Gy} \times 10$ for metastatic epidural spinal cord compression: Final results of the SCORE-2 trial (ARO 2009/01). J Clin Oncol 34: 597-602, 2016.

5 Rades D, Lange M, Veninga T, Rudat V, Bajrovic A, Stalpers LJ, Dunst $J$ and Schild SE: Preliminary results of spinal cord compression recurrence evaluation (SCORE-1) study comparing short-course versus long-course radiotherapy for local control of malignant epidural spinal cord compression. Int J Radiat Oncol Biol Phys 73: 228-234, 2009.

6 Rades D, Lange M, Veninga T, Stalpers LJ, Bajrovic A, Adamietz IA, Rudat V and Schild SE: Final results of a prospective study comparing the local control of short-course and long-course radiotherapy for metastatic spinal cord compression. Int J Radiat Oncol Biol Phys 79: 524-530, 2011.

7 Rades D, Panzner A, Rudat V, Karstens JH and Schild SE: Dose escalation of radiotherapy for metastatic spinal cord compression (MSCC) in patients with relatively favorable survival prognosis. Strahlenther Onkol 187: 729-735, 2011.
8 Rades D, Douglas S, Veninga T, Stalpers LJ, Hoskin PJ, Bajrovic A, Adamietz IA, Basic H, Dunst J and Schild SE: Validation and simplification of a score predicting survival in patients irradiated for metastatic spinal cord compression. Cancer 116: 3670-3673, 2010.

9 Rades D, Walz J, Schild SE, Veninga T and Dunst J: Do bladder cancer patients with metastatic spinal cord compression benefit from radiotherapy alone? Urology 69: 1081-1085, 2007.

10 Joiner MC and Van der Kogel AJ: The linear-quadratic approach to fractionation and calculation of isoeffect relationships. In: Basic clinical radiobiology. Steel GG (ed.). New York, Oxford University Press, pp. 106-112, 1997.

11 Kaplan E and Meier P: Nonparametric estimation from incomplete observation. J Am Stat Assoc 53: 457-481, 1958.

12 Rades D, Fehlauer F, Schulte R, Veninga T, Stalpers LJ, Basic H, Bajrovic A, Hoskin PJ, Tribius S, Wildfang I, Rudat V, Engenhart-Cabilic R, Karstens JH, Alberti W, Dunst J and Schild SE: Prognostic factors for local control and survival after radiotherapy of metastatic spinal cord compression. J Clin Oncol 24: 3388-3393, 2006.

13 Rades D, Douglas S and Schild SE: A validated survival score for breast cancer patients with metastatic spinal cord compression. Strahlenther Onkol 189: 41-46, 2013.

14 Janssen S, Bartscht T and Rades D: Prognosis of patients with metastatic spinal cord compression from adrenocortical carcinoma. In Vivo 30: 717-719, 2016.

15 Rades D, Douglas S, Veninga T and Schild SE: A validated survival score for patients with metastatic spinal cord compression from non-small cell lung cancer. BMC Cancer 12: 302, 2012.

16 Rades D, Douglas S, Veninga T, Bajrovic A, Stalpers LJ, Hoskin PJ, Rudat V and Schild SE: A survival score for patients with metastatic spinal cord compression from prostate cancer. Strahlenther Onkol 188: 802-806, 2012.

17 Bolm L, Janssen S, Bartscht T and Rades D: Radiotherapy alone for malignant spinal cord compression in young men with seminoma. Anticancer Res 36: 2033-2034, 2016.

18 Rades D, Manig L, Janssen S and Schild SE: A survival score for patients assigned to palliative radiotherapy for metastatic bladder cancer. Anticancer Res 37: 1481-1484, 2017.

19 Patchell R, Tibbs PA, Regine WF, Payne R, Saris S, Kryscio RJ, Mohiuddin M and Young B: Direct decompressive surgical resection in the treatment of spinal cord compression caused by metastatic cancer: a randomised trial. Lancet 366: 643-648, 2005.

Received October 22, 2018

Revised October 30, 2018

Accepted October 31, 2018 